\section{Big drug company created}

\section{Washington}

THE UK pharmaceutical concern Beecham Group plc and the US drugs and scientific instruments company SmithKline Beckman last week announced plans to merge in a move that could make them the world's second largest pharmaceutical company in terms of sales.

But despite rumours that the anticipated merger will lead to layoffs of scientific personnel as the new company consolidates its research programmes, a SmithKline Beckman spokesperson says there will be no cutbacks in research.

In the intensely competitive $\$ 127,000$ million worldwide market for pharmaceuticals, SmithKline Beckman and Beecham Group plc have both had stock problems that have made them potential takeover targets in the past year. After hitting its peak as the world's best-selling drug in 1986, SmithKline Beckman's ulcer drug Tagamet experienced an unexpected slump in sales beginning in 1987. Beecham Group plc is just beginning to see the fruits of its economic recovery in both prescription drug sales and over-the-counter preparations and toiletries, after encountering a series of difficulties in the early 1980 s.

After the merger, the new company, SmithKline Beecham, will be virtually untouchable by corporate raiders. Even though neither company has put a price on the deal, analysts estimate the combined company will be worth about $\$ 16,000$ million and will have annual sales of roughly $\$ 5,000$ million.

Separately, neither SmithKline Beckman nor Beecham Group ranks within the top ten drugs companies, but together, SmithKline Beecham may have sales second only to Merck. With a combined sales force of more than 6,000 , SmithKline Beecham hopes to capitalize on the creation of a single European market in 1992, and to compete more effectively in Asia.

The merger is expected to strengthen the research and development programmes of both companies. A planned research and development budget of $\$ 500$ million will boost SmithKline Beecham into the "first tier" of pharmaceutical companies in terms of research and development expenditures, says Niel Sweig of Prudential-Bache Securities. But he says it will still be way behind Merck, which is due to spend $\$ 755$ million on research this year.

The combined company will employ 4,800 researchers, spread out over centres in Pennsylvania and Great Britain, including a \$200-million research and development complex in Pennsylvania opened by SmithKline Beckman in 1986. No research jobs are expected to be eliminated by the merger; the 10,000 layoffs expected in the combined company's 70,000-person workforce will probably come from company administration and pharmaceutical production activities.

As part of the merger, SmithKline Beckman will 'spin off' its Beckman Instruments subsidiary, which means that Beckman Instruments will become a separate company owned entirely by public stockholders, not a parent company. The company's 400 researchers, who work in designing and testing Beckman's centrifuges, chromatography instruments and clinical diagnostic equipment, are expected to remain unaffected. In an internal announcement to employees, Beckman Instruments

\section{SAFETY REGULATIONS}

\section{London}

RESEARCHERs in Britain's universities and research institutions will have to give higher priority to safety to meet the requirements of new legislation which comes into force in October. Before beginning research, they will need to carry out a formal assessment of the risks involved in using any substances that may be hazardous, a term so all-embracing that it includes everything from arsenic to sugar.

The new regulations, called $\mathrm{COSHH}$ (Control of Substances Hazardous to Health), bring research activities under much more strict statutory control. Apart from specific controls relating to, for example, the use of carcinogenic substances or ionizing radiation, the only legal obligation on employers has been to ensure the safety of employees as far as reasonably practical. Now, they must ensure that a risk assessment is carried out and exposure to hazardous substances prevented or controlled.

University safety officers, glad to have the force of law more firmly behind them, have welcomed the COSHH regulations and say that present safety procedures need not be altered significantly, just carried out more systematically.

The safety officer for King's College, London, Roger Slade, says most universities already adhere to the required safety standards. But researchers are less than enthusiastic about carrying out the risk assessments, which they fear will be timeconsuming, and universities fear the costs of taking on extra administrative staff as well as of safety hardware such as fume cupboards.

Despite a huge information campaign by the Health and Safety Executive, there is still confusion among researchers about how detailed the risk assessment will have president Louis Rosso said no changes are contemplated in the company's management or corporate strategy. Beecham Group will sell off its Allergan eyecare products subsidiary as part of the merger.

In the consolidation, to be completed by this summer, Henry Wendt, chairman and chief executive officer of SmithKline Beckman, will become chairman of the new company, and Robert Bauman, executive chairman of Beecham Group plc, will be chief executive.

The headquarters of SmithKline Beecham will be in London, but corporate offices will also be maintained in Philadelphia, Pennsylvania. A complicated stock distribution plan will give SmithKline Beckman and Beecham Group stockholders equal shares in the new company, and pay SmithKline Beckman shareholders a modest dividend.

\title{
Fears on costs of new requirements
}

to be. A working party of the Institute of University Safety Officers has now formulated guidelines on assessment which are being sent to universities this week. In supervised practical teaching of undergraduate and postgraduate work, no assessment specifically to meet the COSHH requirements will be necessary because safety should already be included in existing written protocols for this work, says the institute. And when standard research techniques are being used, no assessment for COSHH will be necessary.

Only when new substances and nonstandard techniques are used, or when an experiment involves a "significant" risk, will a full written assessment be necessary. (Another report is being produced on how to identify research that poses a "significant" risk.)

Christine McGourty

SPACE

\section{NASA chief named}

\section{Washington}

Rear Admiral Richard Truly has been named to succeed James Fletcher as administrator of the National Aeronautics and Space Administration (NASA). A former astronaut, Truly is now head of the office of space flight at NASA. J. R. Thompson, director of the Marshall Space Flight Center in Huntsville, Alabama, is to be nominated as deputy administrator.

Before becoming NASA administrator, Truly must clear two hurdles. First, his nomination must be confirmed by the US Senate, and second, Congress must pass a waiver permitting a former military man to head the civilian space agency. Truly is now on active status in the Navy, but will resign his commission. Neither hurdle is expected to be difficult to clear. 